\title{
Minimum Angle of Resolution
}

National Cancer Institute

\section{Source}

National Cancer Institute. Minimum Angle of Resolution. NCI Thesaurus. Code C142233.

The smallest angle of separation that allows an image-forming device to distinguish two objects as distinct entities. 